\title{
DEVELOPMENT AND COMPARISON OF FOUR GA BASED ALGORITHMS FOR HETEROGENEOUS VEHICLE ROUTING PROBLEM WITH TIME WINDOWS
}

\author{
SACHIN KUMAR NAGLE ${ }^{1} \&$ R. PANNEERSELVAM ${ }^{2}$ \\ ${ }^{I}$ Department of Management Studies, School of Management, Pondicherry University, Pondicherry, India \\ ${ }^{2}$ Professor, Department of Management Studies, School of Management, Pondicherry University, Pondicherry, India
}

\begin{abstract}
Heterogeneous Vehicle Routing Problem with Time Windows is the most practical variant of Vehicle Routing Problem due to its complexity. It belongs to the NP-Hard combinatorial problem. Because of its applications, it has become a popular choice among researchers and practitioners. In the first part of this research, a brief introduction of supply chain management has been provided. Then, an extensive literature review on various meta-heuristics for solving the Heterogeneous Vehicle Routing Problem and its variants has been presented. Based on the brief literature review, the Heterogeneous Vehicle Routing Problem with Time Windows is selected as the research problem. Since Heterogeneous Vehicle Routing Problem with Time Windows is combinatorial and NP-Hard in nature, in this research, four metaheuristics based on Genetic Algorithm are developed for solving it. The proposed four algorithms are compared using a Complete Factorial Experiment with three factors, viz. GA Method, Problem Size and Mutation Probability. Since the factor "GA Method" is significant, the best algorithm has been identified by using Duncan's Multiple Range Test.

KEYWORDS: Heterogeneous, Algorithm \& Customers
\end{abstract}

Received: Jun 09, 2020; Accepted: Jun 29, 2020; Published: Aug 06, 2020; Paper Id.: IJMPERDJUN2020652

\section{INTRODUCTION}

The growth of an organization greatly depends on activities like Supply Chain Management (SCM), which involves the movement and storage of resources from the point of origin to the point of consumption. The SCM does the task of picking up raw materials and semi-finished items from suppliers and bringing them to the manufacturing plants either through raw material warehouses or directly. Later, the finished products may be shipped to the customers either directly or through finished goods warehouses. The entire process comes under business logistics. Due to its importance, many companies are trying to develop efficient methods to increase customer satisfaction and reduce costs. In addition to this activity, at the distribution side of companies, the items will be delivered to customers directly at regular intervals. For example, in the Food Supply Chain of government, the food grains are to be shipped to different fair-price shops using heterogeneous vehicles once in a month. So, each heterogeneous vehicle which initiates its trip from a depot of Food Corporation of India (FCI) has to visit different fair-price shops to deliver the items and then return to the depot of FCI.

SCM deals with the management of activities, which are directly or indirectly responsible for satisfying the demands of the end-users. These activities are not only including the manufacturers and suppliers, but also include transporters, warehouses, retailers as well as customers. These activities are recurrent in the overall supply chain. Along with this, information and capital are also moving in the direction of the supply chain. It is not necessary that only one participant is involved in each activity. In the real-life scenario, there can be more than one participant. In 
this context, Heterogeneous Vehicle Routing Problem with Time Windows (HVRPTW) has been considered for this research.

\section{Heterogeneous Vehicle Routing Problem}

Gendreau et al. (1999) considered the Heterogeneous Vehicle Routing Problem (HVRP) in their research. The objective of this problem is to determine the optimum route for the heterogeneous vehicles in order to satisfy the constraints of the Vehicle Routing Problem (VRP). These constraints are such that each route must start and end at the same depot, each customer must served exactly once by a vehicle, the requirements of the route should not exceed the capacity of the vehicle which is assigned to it and the vehicle(s) used in the problem are heterogeneous, which means that the vehicles will have different capacity and costs. The objective of this problem is to determine a set of routes in order to minimise the total operating costs or total time of the route.

\section{Heterogeneous Vehicle Routing Problem with Multiple Product with Time Windows}

Jair et al. (2013) developed a tabu search algorithm for solving the Heterogeneous Vehicle Routing Problem with Multiple Products with Time Windows. This problem consists of the three constraints simultaneously with the constraints of VRP. The three constraints of this problem are such that the vehicles involved are not identical, which means they have different capacities and cost, the vehicle can carry multiple products, and the customers have their own time windows in which service should be completed. The objective of this problem is to find out the tours of the heterogeneous vehicles with minimum total cost or minimal tour time.

\section{Heterogeneous Vehicle Routing Problem with Time Windows}

One of the most practical extensions of the VRP is the HVRP. HVRP was introduced by Golden et al. (1984), and it has evolved as a crucial field of research. Further, it is a NP-Hard combinatorial problem. The extension of VRP aims to serve a group of customers with minimum cost and a limited number of vehicles having different capacities. Other extensions of HVRP include studies like Dondo et al. (2007), Xu et al. (2012), Behrouz \& Alireza (2017), who considered the multidepot routing problem with time windows and heterogeneous vehicles. De et al. (2013), Amador-Fontalvo et al. (2014) and Kabcome et al. (2015) present soft time windows and the distribution of products with multiple categories. In this context, Jabali et al. (2016) and Nagle and Pannerselvam (2016) provided an extensive survey of the literature on HVRP and its variants.

The HVRPTW is a more practical approach of SCM in the present scenario with the increased flow of goods to satisfy customer demand. The ultimate objectives of this problem is to determine the optimal route of heterogeneous vehicles in order to minimize the total operating cost of the vehicles and minimise the total time taken for completing the tour by heterogeneous vehicles, while satisfying all the constraints of VRP and other constraints such as service for each customer must start within the time windows of the customers, each route starts at a depot and ends at the same depot. The total demand of the customers served on each route must not exceed the capacity of the associated vehicle; the services will start and finish at the customer points within the time windows. If a vehicle reaches the customer location before the time window, then it has to wait there, and if the vehicle reaches after the time windows, then it is penalized. 


\section{LITERATURE REVIEW}

This section presents a review of literature on various meta-heuristics for solving the HVRP and its variants. Alvarenga et al. (2007) presented a two-phase method based on Genetic Algorithm and Set Partitioning formulation for solving the vehicle routing problem with time windows. The results of the proposed method are better than other well-known and published heuristic in available literature for minimising the total travel distance. Kumar and Pannerselvam (2015) solved a time-dependent vehicle routing problem with time windows for E-commerce supplier's site pickups by using the genetic algorithm. On the basis of results, they claim that the proposed algorithm gives better results in terms of minimising the total distance travelled and minimizing the number of vehicles. Kallel and Boujelbene (2013) considered the heterogeneous vehicle routing problem and dynamic problem in their study. They proposed the new approach based on the genetic clustering algorithm for solving this problem. The computation results show that the proposed approach is able to solve this problem effectively. Pierre and Zakaria (2017) developed the stochastic partially cyclic shift crossover operator for the Multi-Objective VRP with time windows by using the Genetic Algorithm. The results of the proposed method show that it provides competitive results. Jiang et al. (2014) considered the new extension of the VRP, which is a VRP with a Heterogeneous Fleet with Time Windows. They proposed the extended method based on Tabu Search Algorithm for solving this problem. The results show that this method gives competitive results for the defined problem.

Sadouni (2006) selected the Tabu Search Algorithm for solving the Heterogeneous Fleet VRP with Time Windows. They found that the selected method is able to solve this problem effectively. Li et al. (2012) presented the Heterogeneous Fixed Fleet Open VRP to solve this problem. They considered the multi-start adaptive memory-based Tabu Search Algorithm in their study and concluded that the considered algorithm generates a quality solution. Kirci (2016) used the Tabu Search Algorithm and Hopfield neural networks for solving the VRP with Time Windows. In this problem, they considered the real scenario constraints as a real-world application on google maps. The objective of this method is to develop the optimum path as per the demands of the customers. The author has used the Simulated Annealing Algorithm for the comparison of the results of the algorithm, and it was found that the Tabu Search Algorithm is performing well with 95\% confidence level at the visited path in kilometres. Braysy et al. (2008) presented the new Deterministic Annealing Meta-heuristics for the fleet size and Mix VRP with Time Windows. On the basis of results, they claimed that the proposed algorithm is able to generate good results as compared to other algorithms. Despaux and Basterreach (2016) introduced a meta-heuristic approach based on local search and Simulated Annealing Algorithm for solving the Multi-Trip VRP with Time Windows and Heterogeneous Fleet. It has been seen that the proposed method is performing well. Pace et al. (2015) considered the Heterogeneous Fleet Capacitated VRP with Time Windows and three-dimensional loading constraints. They developed a loading algorithm based on a depth-first search method for solving this problem. This loading module is tested after implementing a Simulated Annealing Algorithm approach as a route optimisation procedure. They concluded that the developed algorithm is effective in producing better solutions in terms of delivery of all items within the time windows that are to be delivered on a particular day. Caschia et al. (2011) presented the Tabu Search algorithm for the HVRPTW and carrier dependent costs. For solving this problem, they proposed meta-heuristics based on the Tabu Search with a combination of Neighbourhood Relation. They observed that there has been significant improvements in the results obtained by the proposed algorithm that are competitive as compared to similar algorithms. Liu (2013) presented a hybrid population heuristic for the HVRP. In this study, they presented two variants of this problem, viz. one which considers the fixed and variable cost and another which considers only the variable cost. The results show that the proposed method is giving good results in less computational time. Koc et al. (2015) developed the hybrid evolutionary algorithm for solving 
the HVRPTW. They presented four variants of this problem, the first two are based on fleet size and mixed VRP with time windows, and the other two are HVRPTW. They combined two algorithms, viz. heterogeneous adaptive large scale neighbourhood search and population search. The results are quite competitive than well-known algorithms. Prins (2009) considered the HVRP and the vehicle fleet mix problem with an unlimited number of vehicles per type. For solving this problem, they presented the two memetic algorithms by using Genetic Algorithms which hybridized with a local search to solve both the problems. They concluded that the proposed algorithm is better than the other algorithms. Imran et al. (2009) presented the HVRP. They considered the Variable Neighbourhood Search Algorithm in their study for solving this problem. The results of this method have been tested on several benchmark data sets and are seen as competitive and effective. Hu et al. (2013) solved the VRP with Time Windows by using the unique algorithm known as hybrid chaosparticle swarm optimization algorithm. They tested and compared this algorithm with other algorithm and claimed that the proposed algorithm is better than the other algorithms.

\section{Research Gap}

Based on the literature review, the findings are listed below.

- On the basis of the review of literature, it is found that the only few studies considered the HVRPTW.

- Out of this study, it is found that a comprehensive crossover method for GA to solve HVRPTW is not available

Hence, a new Crossover method is developed in this research. Based on this crossover method and four different selection methods, four modified meta-heuristics based on genetic algorithm are developed for solving HVRPTW. Then the proposed four algorithms are compared using a complete factorial experiment with three factors, viz. Problem Size and Method and Mutation Probability. Since the factor "Method" is significant, the best algorithm has been identified by using Duncan's Multiple Range tests.

\section{OBJECTIVES OF RESEARCH}

The objectives of the research reported in this paper are listed below.

- To develop a new crossover method for Genetic Algorithm.

- To develop the four different variants of the Genetic Algorithm by combining developed Crossover Method with four selection methods viz. rank selection method, roulette wheel selection method, random selection method and tournament selection method.

- To solve the HVRPTW in order to minimise the total time taken for completing the tour by using these algorithms.

- To compare and identify the best algorithm among the four developed algorithms, in terms of generating good results near optimally.

\section{BASICS OF GENETIC ALGORITHM}

Genetic Algorithm (GA) is an adaptive heuristic search algorithm based on the evolutionary ideas of natural selection. The basic concept of the GA is designed by using the theory of "survival of the fittest", developed by Charles Darwin. The solution of GA typically involves some basic steps viz. representation, selection, recombination (crossover), and mutation. In the first step, the representation of chromosomes represents the substantial structures of a solution. Chromosomes 
defined as the individual members of a population are naturally seen by a bit string. A chromosome is a combination of genes. Genes are having the basic features of a solution (Paneerselvam 2016). The selection step involves choosing different chromosomes from the old population for crossover. The step of recombination or reproduction process uses the genes of selected parents to generate offspring for the next generation.

\section{Basic Steps of Genetic Algorithm}

The basic structure of GA is presented below (Chand and Mohanty 2013).

- Step 1: Randomly initialize the population.

- $\quad$ Step 2: Set the maximum generation.

- Step 3: Initialize the generation count as one.

- Step 4: Evaluate the fitness function of each chromosome in the population

- $\quad$ Step 5: While (generation count $\leq$ maximum generation)

\{

- Step 5(a): Sort the chromosomes in ascending order or descending order for minimization or maximization type of objective function, respectively.

- Step 5(b): Apply selection procedure to select a set of chromosomes from the population, for the next generation

- Step5(c): Apply genetic operators (crossover and mutation) for the chromosomes of the subpopulation to obtain their offspring.

- Step 5(d): Replace the chromosomes of the population by their corresponding offspring.

- $\quad$ Step 5(e): Set Generation count $=$ Generation count +1

\} .

- Step 6: Treat the topmost chromosome of the last generation as the solution for implementation.

\section{Crossover Operators}

Crossover operation is a dynamic step for generating new offspring by combining two or more parent chromosomes. These offspring replace parent chromosomes for the next generation. The main objective of the crossover step is to make copies of good solutions while eliminating unfair solutions in a population in order to keep the population size constant. Some selected crossover methods presented by various researchers to solve HVRPTW are listed below.

\section{Best Cost Route Crossover Method}

Best Cost Route Crossover Method (BCRC) Method is a problem-specific crossover operator method. It was first proposed by Ombuki et al. (2006). The main objective of the BCRC method is to minimize the number of vehicles and the cost simultaneously, which are associated with the operation of the vehicles, subject to satisfying all the constraints. The steps of this crossover method are presented below. 
- $\quad$ Assume two parents, viz: parents P1 and P2 and two offspring OF1 and OF2 as shown below.

$\begin{array}{lrllllllll}\text { P1: } & 9 & 8 & 2 & 4 & 6 & 5 & 7 & 1 & 3 \\ \text { P2: } & 3 & 7 & 5 & 6 & 4 & 2 & 8 & 9 & 1 \\ \text { OF1: Null } & & & & & & & & & \end{array}$

- $\quad$ Randomly select two cut points on P1 and P2 for creating substring

\begin{tabular}{|c|c|c|c|c|c|c|c|}
\hline \multirow[b]{2}{*}{ P1: } & \multicolumn{3}{|c|}{ Substring1 } & \multicolumn{2}{|c|}{ Substring 2} & \multicolumn{2}{|c|}{ Substring 3} \\
\hline & 9 & 8 & 2 & |46| & 5 & 7 & 13 \\
\hline P2: & 3 & 7 & 5 & |6428| & & 9 & 1 \\
\hline
\end{tabular}

- From each parent, a substring is chosen randomly. From parent P1, the substring consisting of genes 4 and 6 is chosen, and from parent P2, the substring consisting of genes 9 and 1 is chosen. Then, delete the genes present in the substring of a parent from the substrings of the other parent to create offspring. The resulting partial

Offspring are as shown below.

\begin{tabular}{|c|c|c|c|c|c|c|}
\hline \multirow[b]{2}{*}{ OF1: } & \multirow{2}{*}{$\begin{array}{c}\text { Substring } 1 \\
82\end{array}$} & \multicolumn{2}{|c|}{ Substring 2} & \multicolumn{3}{|c|}{ Substring 3} \\
\hline & & 4 & 6 & 5 & r & \\
\hline OF2: & 375 & 12 & 8 & 9 & 1 & \\
\hline
\end{tabular}

- $\quad$ Placing genes of a selected string of one parent in the offspring corresponding to another parent.

Note: In this step, the operator will place the genes of the selected string in the best possible location in the corresponding offspring.

- $\quad$ Placing of the genes of substring $3(9,1)$ of parent P2 in the partial offspring 1.

- Choose any of the genes from the substring $(9,1)$ of the parent $\mathrm{P} 2$ randomly.

Let it be gene 9 .

For extending the offspring OF1, the feasible locations in it for gene 9 are listed as follows. Further, each of the following locations is a feasible location, because the capacity of the vehicle assigned to that substring is sufficient to take up the load of the new gene, which is to be inserted in it now.

A- Gene 9 can be inserted before gene 8 and after gene 8 .

B- Gene 9 can be inserted after gene 2 .

By following the above logic, the extended offspring OF1, which is obtained from the earlier partial offspring 1 is as follows by locating the gene 9 after gene 7 .

$\begin{array}{lll}\text { Substring1 } & \text { Substring } 2 \quad \text { Substring } 3\end{array}$

OF1: $\quad \begin{array}{llllll}82 & |46| & 5 & 7 & 9 & 3\end{array}$

- Placing one of the genes of substring 2 (4 6) of the parent P1 in the partial offspring 2 (OF2).

- Choose any of the genes from the substring2 (4 6) of the parent P1 randomly.

Let it be gene 4 . 
- For extending the partial offspring OF2, the feasible locations in it for gene 4 in the selected string of the parent P1 are as follows. Each of the following locations is a feasible location because the capacity of the vehicle assigned to that substring is sufficient to take up the load of the new gene, which is to be inserted in it.

A- Gene 4 can be inserted before the gene 3 and after gene3.

B- Gene 4 can be inserted after gene 7 .

C- Gene 4 can be inserted after gene 5

D- Gene 4 can be inserted before the gene 2 and after gene2.

E- Gene 4 can be inserted after gene 8

F- Gene 4 can be inserted before the gene 9 and after gene 9

G- Gene 4 can be inserted after gene 1

By following the above logic, the extended offspring OF2, which is obtained from the earlier partial offspring 2 is as follows by locating it before gene 9 .

Substring1 Substring $2 \quad$ Substring 3

$\begin{array}{llll}\mathrm{OF} 2: 3754 & |28| & 9 & 1\end{array}$

- For modifying the latest partial offspring OF1, the feasible locations in it for gene 1 of the selected string of the parent $\mathrm{P} 2$ are as follows. Each of the following locations is a feasible location because the capacity of the vehicle assigned to that substring is sufficient to take up the load of the new gene, which is to be inserted in it.

By following the above logic, the modified offspring OF1, which is obtained from the previously formed offspring OF1 is as follows by locating the gene 1 be after gene 3 .

\begin{tabular}{cccccccc} 
& Substring1 & Substring 2 & \multicolumn{2}{c}{ Substring 3} \\
OF1: & 82 & $|46|$ & 5 & 7 & 9 & 3 & 1
\end{tabular}

- For modifying offspring OF2, the feasible location in it for the gene 6 of the selected string of the parent P1 is after the gene 3 in it, and accordingly, it is inserted as shown below. The insertion of the gene 6 after the gene 3 is possible because the vehicle capacity is sufficient to take that node in that substring, which represents a route from the depot to different nodes and back to the depot.

\begin{tabular}{|c|c|c|c|}
\hline & Substring1 & Substring 2 & Substring 3 \\
\hline $\mathrm{OF}_{2}$ : & $\begin{array}{llll}3 & 6 & 7 & 5\end{array}$ & $\left|\begin{array}{ll}2 & 8\end{array}\right|$ & 9 \\
\hline
\end{tabular}

The location of the placement of a gene in an offspring is called infeasible, if it is not satisfying the constraints like "not meeting the vehicle capacity" or "not satisfying time window" and that it is called feasible if it satisfies all the constraints.

\section{Selection Methods}

In GA, the following selection methods as listed below are used to improve the solution efficiency. 
- Rank Selection Method,

- Roulette Wheel Selection Method,

- Random Selection Method,

- Tournament Selection Method

A selection method guides the investigator to select two parent chromosomes by following some steps. The above selection methods are explained in the following subsections.

\section{Rank Selection Method}

In the rank selection method, the chromosomes are to be sorted according to their fitness function values, either in ascending order or in descending order depending on the type of fitness function. The ascending order is followed for the minimization type of fitness function and descending order is followed for the maximization type of fitness function.

\section{Roulette Wheel Selection Method}

This selection method selects the chromosomes proportionate to their fitness function value. If any chromosome has the high fitness function value, then the chance of that chromosome getting selected is also high. This selection method works on the principles of linear search through a roulette wheel with the slots in the wheel weighed in proportion to the individual fitness function values. The selection probability is given by Jebari \& Madiafi (2013). It is a very simple selection method for implementing, which takes the least computational time. However, sometimes, it suffers from the problem of early convergence, which affects finding the solution that is locally optimum. Steps of the Roulette wheel selection method are as follows.

- Step-1: Let $\mathrm{N}$ be the number of chromosome in the population.

- Step-2: Find the sum of the fitness function value of all the chromosome in the population.

Let it be SFFV.

- Step-3: Find the proportion of FFV (I) of each chromosome (I) in the population over the sum of the fitness function value.

$$
\begin{aligned}
& \text { For } \mathrm{I}=1 \text { to } \mathrm{N} \text { do } \\
& \qquad \begin{array}{l}
\left\{(I)=\frac{F F V(I)}{S F F V}\right. \\
\}
\end{array}
\end{aligned}
$$

- Step-4: Initialize the end of cumulative probability of the first interval using the following formula.

$$
\mathrm{CP}(\mathrm{I})=\mathrm{p}(1)-0.01
$$

- $\quad$ Step-5: for $\mathrm{I}=2$ to $\mathrm{N}$ do

$$
\mathrm{CP}(\mathrm{I})=\mathrm{CP}(\mathrm{I}-1)+\mathrm{p}(\mathrm{I})
$$


- $\quad$ Step -6: $\mathrm{J}=1$

- Step-7: Generate uniformly distributed random number $\mathrm{R}$ in the range from 0 to 0.99 .

- Step-8: Selection of chromosome for crossover.

For $\mathrm{I}=1$ to $\mathrm{N}$ do

$$
\text { If } \mathrm{R}_{\mathrm{CP} \text { (I) then go to step } 9}
$$

\}

- Step-9: If chromosome I is already selected, then go to step 7; otherwise go to step 10.

- Step-10: Store the chromosome I as the $\mathrm{I}^{\text {th }}$ chromosome for crossover.

- Step-11: J=J+1

- Step -12: If J $\leq_{2}$ then go to step 7, else go to step 13

- Step-13: Continue for the crossover step.

\section{Random Selection Method}

Random selection method selects the chromosome randomly from the initial population. There is no particular method for selecting the parent chromosomes, and all chromosomes have an equal probability for getting selected.

- Step-1: Let $\mathrm{N}$ be the number of chromosome in the population.

- Step-2: Find an equal probability for each chromosome in the population.

$$
\text { For } \mathrm{I}=1 \text { to } \mathrm{N} \text { do }
$$

$$
\{
$$

$$
p(I)=\frac{1}{N}
$$

\}

- $\quad$ Step-3: Initialise CP (I) $=\mathrm{p}(1)-0.01$

- $\quad$ Step-4: for $\mathrm{I}=2$ to $\mathrm{N}$ do

\{

$$
\mathrm{CP}(\mathrm{I})=\mathrm{CP}(\mathrm{I}-1)+\mathrm{p}(\mathrm{I})
$$

\}

- $\quad$ Step -5: J=1

- Step-6: Generate uniformly distributed random number $\mathrm{R}$ in the range from 0 to 0.99 . 
- Step-7: Selection of chromosome for crossover.

For $\mathrm{I}=1$ to $\mathrm{N}$ do

$$
\text { If } \mathrm{R} \leq \mathrm{CP}(\mathrm{I}) \text { then go to step } 8
$$

\}

- Step-8: If chromosome I is already selected, then go to step 6; otherwise go to step 9.

- $\quad$ Step-9: Store the chromosome I as the $\mathrm{J}^{\text {th }}$ chromosome for crossover.

- $\quad$ Step-10: $\mathrm{J}=\mathrm{J}+1$

- Step -11: If $\mathrm{J} \leq 2$ then go to step 6 , else go to step 12

- Step-12: Continue for the crossover step.

\section{Tournament Selection Method}

The tournament selection method selects the chromosomes from the large population, and then they contest against each other. The chromosome, which has the best fitness function value wins this contest and is selected for the crossovers. Tournament size is the number of chromosomes participating in the contest. This method gives equal opportunity to every chromosome for contesting, which conserves the variety. The selection probability is given by Jebari \& Madiafi (2013). In this method, selection pressure can be adjusted by changing the tournament size. Parallel architecture is used in this method. Steps of the tournament selection method are as follows.

- Step-1: Let M be the number of participating chromosomes, which need to be equal to the size of the population.

- Step-2: Find the equal probability for each chromosome in the population.

$$
\text { For } \mathrm{I}=1 \text { to } \mathrm{M} \text { do }
$$

$$
\mathrm{p}(\mathrm{I})=1 / \mathrm{M}
$$

- $\quad$ Step-3: Initialise CP (I) $=\mathrm{p}(1)-0.01$

- Step-4: for $\mathrm{I}=2$ to $\mathrm{M}$ do

$$
\mathrm{CP}(\mathrm{I})=\mathrm{CP}(\mathrm{I}-1)+\mathrm{p}(\mathrm{I})
$$

\}

- $\quad$ Step -5: $\mathrm{J}=1$

- $\quad$ Step-6: Generate uniformly distributed random number $\mathrm{R}$ in the range from 0 to 0.99 . 
- Step-7: Selection of chromosome for crossover.

For $\mathrm{I}=1$ to $\mathrm{M}$ do

$$
\text { If } \mathrm{R}_{\mathrm{CP} \text { (I) then go to step } 8}
$$

\}

- Step-8: If chromosome I is already selected, then go to step 6; otherwise go to step 9.

- Step-9: Store the chromosome I as the $\mathrm{J}^{\text {th }}$ chromosome for crossover.

- Step-10: $\mathrm{J}=\mathrm{J}+1$

- $\quad$ Step -11: If J $\leq_{2}$ then go to step 6, else go to step 12

- Step-12: Continue for the crossover step.

\section{CROSSOVER METHOD AND FITNESS FUNCTION OF NEW GENETIC ALGORITHMS}

The performance of the genetic algorithm depends on the crossover method that is used in it. Further, the fitness function, which computes the desired measure of performance, depends on the objective of the problem that is solved using the genetic algorithm. These are presented in the following sections.

\section{N\&P Crossover Method}

Based on an extensive review of literature, Nagle and Panneerselvam (2018) found that the traditional crossover methods are not very conducive to optimize the problem of HVRPTW. So, an attempt has been made to a solve HVRPTW problem based on a practical crossover method. The steps of the proposed crossover method, which is named as N\&P Crossover Method, are as follows.

- Step1: Let us assume that two parents chromosome viz. P1and P2are as follows:

$$
\begin{aligned}
& \text { P1: } 1 \quad \text {--9--3--7-8 --17--13--16-20 -- } \quad \text { 14--15--10--19-18 -- } 4--\quad 5-12 \text {-- 6-- } 11 \text {--2 } \\
& \text { P2: 3-- } \quad 10--5-12 \quad--16--2--4-13--14--\quad \text { 18--15--20--1--7-6-- 9-- } 11--19-17 \quad 8
\end{aligned}
$$

- Step 2: Assume 9 available vehicles, A1, A2, A3, B1, B2, B3, C1, C2, and C3 with different capacities as shown below.
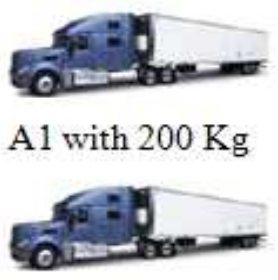

B1 with $250 \mathrm{Kg}$

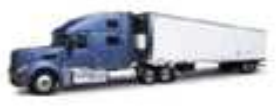

C1 with $300 \mathrm{Kg}$

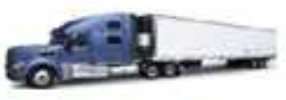

A 2 with $200 \mathrm{Kg}$
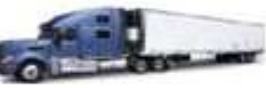

B2 with $250 \mathrm{Kg}$

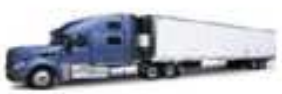

C2 with $300 \mathrm{Kg}$

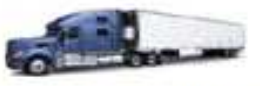

A3 with $200 \mathrm{Kg}$

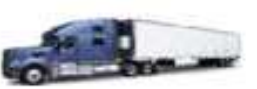

B3 with $250 \mathrm{Kg}$

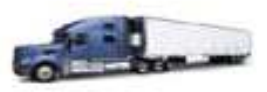

C3 with $300 \mathrm{Kg}$ 
- Step 3: Randomly select three cut points, viz. gene position 17, gene position 10 and gene position 12 on P1 and gene position 16, gene position 15 and gene position 11 on P2 for creating the sub-routes. The sub-routes of P1 and $\mathrm{P} 2$ are as shown below.

\section{From P1}

Sub route 1

Sub route 2

Sub route 3

Sub route 4

$1--\quad 9---3---7$---8 ---17

13--- 16--- 20--- 14--- 15--- 10

$19 \quad---18$

6--- 11-- 2

From P2

Sub route 1

Sub route 2

Sub route 3

Sub route 4

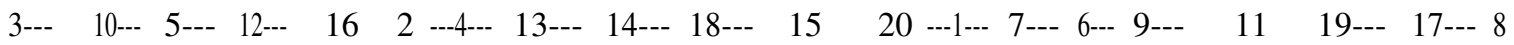

- Step 4: Let assume that the demand values of the sub-routes as follows.

Parent P1:

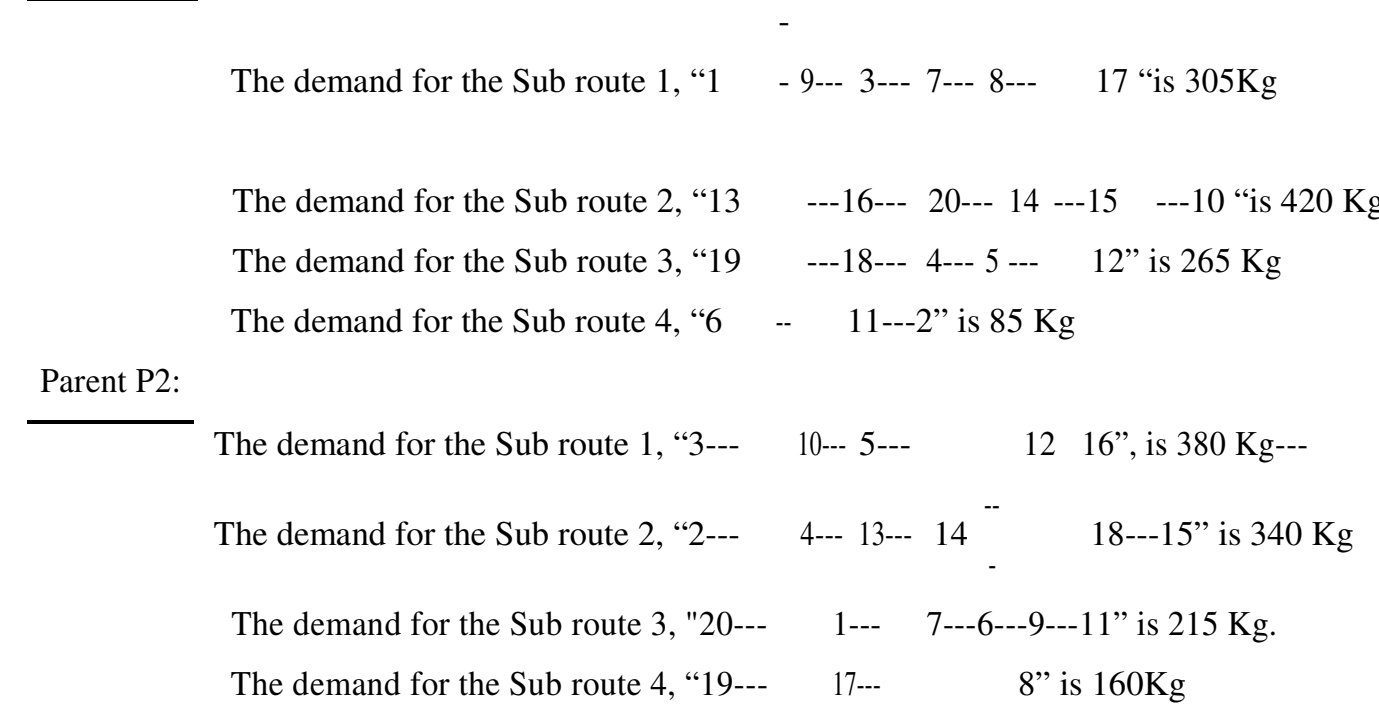

- Step 5: In this step, select one sub route which is having maximum demand from each parent and simultaneously remove these from the opposite parent. Suppose the sub route that is with

genes 13--- 16--- 20---14---15 ---10 is selected from P1 and sub route 1 that is with genes $3 \quad$---10--5--12--- $\quad 16$ is selected from P2. After performing this step, new offspring will be as follows.

From P1

Sub route 1

Sub route 2

Sub route 3

Sub route 4

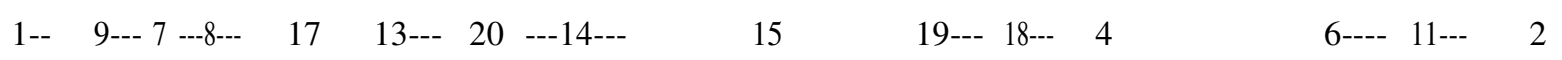

From P2

Sub route 1

Sub route 2

Sub route 3

Sub route 4

3--- 5--- 12

2--- 4--- 18

1--- 7--- 6--- 9---

11

19--- 17--- 8

After removing the genes, the demand for remaining offspring are as follow.

Offspring 1:

The demand for the Sub route 1, "1-- 9--- 7--- 8--- 17 "is $265 \mathrm{Kg}$

The demand for the Sub route 2, "13--- 20--- 14-- 15 "is $245 \mathrm{Kg}$

The demand for the Sub route 3, "19--- 18---4" is $120 \mathrm{Kg}$ 
The demand for the Sub route 4, "6-$11--2$ " is $85 \mathrm{Kg}$

Offspring2:

The demand for the Sub route 1, "3---

512 ", is $205 \mathrm{Kg}$---

The demand for the Sub route 2, "2--$4---18 ”$ is $145 \mathrm{Kg}$

The demand for the Sub route 3, "1--7--- 6--- 9--- 11 ” is $165 \mathrm{Kg}$.

The demand for the Sub route 4, "19--- $\quad 17---\quad 8$ " is $160 \mathrm{Kg}$

Assume the demands of the removed genes as given below.

$$
\begin{aligned}
& 13=55 \mathrm{Kg}, \quad 16=85 \mathrm{Kg}, \quad 20=50 \mathrm{Kg} \quad 14=65 \mathrm{Kg} .15=75 \mathrm{Kg} \quad 10=90 \mathrm{Kg} \text {. } \\
& 3=60 \mathrm{Kg}, \quad 10=90 \mathrm{Kg}, \quad 5=100 \mathrm{Kg} \quad 12=45 \mathrm{Kg} .16=85 \mathrm{Kg}
\end{aligned}
$$

- Step 6: Since each chromosome should contain all the genes; the next step is to insert there moved genes into the best possible places in the corresponding offspring. For this, some basic steps are to be followed, which are presented below.

- Step 6.1: Arrange the available heterogeneous vehicle in increasing order according to their capacity. Accordingly, the new arrangement of the vehicle is as follows:

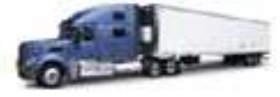

A1 with $200 \mathrm{Kg}$

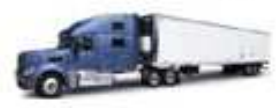

B1 with $250 \mathrm{Kg}$

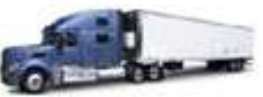

C1 with $300 \mathrm{Kg}$
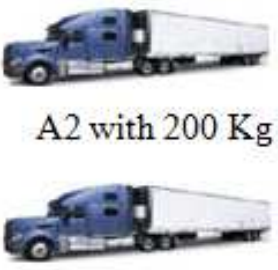

B2 with $250 \mathrm{Kg}$

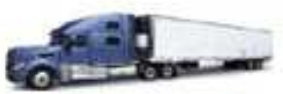

C2 with $300 \mathrm{Kg}$
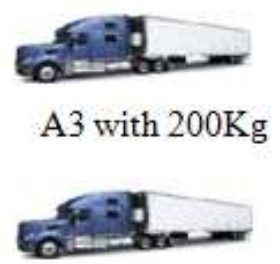

B3 with $250 \mathrm{Kg}$

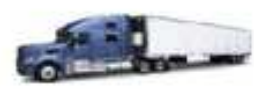

C3 with $300 \mathrm{Kg}$

- Step 6.2: Arrange the substrings of each offspring in the increasing order of their demand values, as shown below.

From P1

Sub route 4

Sub route 3

Sub route 2

Sub route 1
6---- $11 \quad$---2
19 ---18--- 4
13 ---20 --- 14---
\begin{tabular}{llllll}
15 & 1 & -- & 9 & ---7 & ---8 \\
\hline---
\end{tabular}

From P2

Sub route 2

Sub route 4

Sub route 3

Sub route 1

$2 \quad---4--\quad 18$

19--- 17--- 8 1--- $\quad 7$--- 6--- 9--- 11

3--- 5--

- Step 6.3: Insert the removed gene 3--- 10--- 5---12 ---16 at the end of each sub route of P1 starting from left to right and check the resultant demand of that sub route. The first check is with gene 3 . As per this, insert the gene 3 on the suffix of sub route 4 .

From P1

Sub route 4 Sub route 3

Sub route 2

Sub route 1

$6 \begin{array}{llllllllllll}----11 & ---2 & ---3 & 19 & ---18 & ---4 & & \end{array}$ 
- Step 6.4: Now match the sub route with the vehicle capacity and find out the best possible way for inserting the removed genes. If the gene 3 is put in the sub route 4, then the demand for that sub route will be $145 \mathrm{Kg}$, and we have a vehicle by which we can fulfill this demand. So the gene 3 should be inserted on sub route 4 . After following this step the partially formed tour is shown below.

From P1

Sub route 4 Sub route 3

Sub route 2 Sub route 1

6 ----11 ---2 $\quad---3 \quad 19 \quad---18 \quad$---4 $\quad 13---\quad 20$---14--- $15 \quad 1 \quad$-- 9--- 7 ---8--- 17

- Step 6.5: Insert the removed gene 10---5---12---16 at the end of each sub route of P1startingfrom left to right and check the resultant demand of that sub route. The next check is with the gene 10. As per this, insert the gene 10 on the suffix of sub route 4 .

From P1

Sub route 4 Sub route 3 Sub route 2 Sub route 1

6 ----11 ----2-- 3--- $10 \quad 19 \quad---18 \quad$---4 $13 \quad 13 \quad$---20 ---14 ---15 19 1-- 9--- 7 ---8--- 17

- Step 6.6: Now match the sub route with the vehicle capacity and find out the best possible way for inserting the removed genes. If gene ten is put in the sub route 4, then the demand for that sub route will be $235 \mathrm{Kg}$, and we have a vehicle by which we can fulfill this demand. So, the gene 10 should be inserted on sub route 4 . After following this step the partially formed tour is shown below.

From P1

Sub route 4

Sub route 3

Sub route 2

Sub route 1

6

- Step 6.7: Insert the removed gene 5--- 12 ---20 ---14 ---15 1-- 9--- 7 ---8--right and check the resultant demand of that sub route. The next check is with gene 5 . As per this, insert the gene 5 on the suffix of sub route 4 .

From P1

Sub route 4 Sub route 3 Sub route 2

Sub route 1

6 ----11 ---2--- 3--- 10 ----5

$19 \quad---18 \quad---4$

$13 \quad---20 \quad---14---\quad 15 \quad 1 \quad--9$---7

- Step 6.8: Now match the sub route with the vehicle capacity and find out the best possible way for inserting the removed genes. If the gene 5 is put in the sub route 4, then the demand for that sub route will be $335 \mathrm{Kg}$, and we don't have a vehicle by which we can fulfill this demand. So, try with another sub route.

From P1, the sub-routes are as follows.

Sub route $4 \quad$ Sub route 3

Sub route 2

Sub route 1

6 ----11 ---2 ---3--- $10 \quad 19 \quad---18 \quad---4 \quad$---5 $13 \quad 13 \quad$---20

- Step 6.9: Now match the sub route with the vehicle capacity and find out the best possible way for inserting the removed genes. If the gene 5 is put in the sub route 3, then the demand for that sub route will be $220 \mathrm{Kg}$, and we have a vehicle by which we can fulfill this demand. So, the gene 10 should be inserted on sub route 4 . After following this step the partially formed tour is shown below. 
From P1

Sub route 4 Sub route 3

Sub route 2

Sub route 1

6 ----11 ----2--- 3--- $10 \quad 19 \quad---18 \quad---4 \quad---5$

13

$---20 \quad---14---\quad 15$

$1--\quad 9$---7 ---8--- 17

- Step 6.10: Insert the removed gene 12---16 at the end of each sub route of P1start from left to right and check the resultant demand of that sub route. The next check is with the gene 12 insert the gene 12 on the suffix of sub route 4 .

From P1, the sub-routes are as follows.

Sub route 4

Sub route 3

Sub route 2

Sub route 1

6 ----11 ---2 ----3--- 10 ---12 19 ---18

$13 \quad---20 \quad---14---\quad 15$

$1 \quad--9$---7 ---8--- 17

- Step 6.11: Now match the sub route with the vehicle capacity and find out the best possible way for inserting the removed genes. If gene 12 is put in the sub route 3, then the demand for that sub route will be $280 \mathrm{Kg}$, and we have a vehicle by which we can fulfil this demand. So, the gene 12 should be inserted on sub route 4 . After following this step, the partially formed tour is shown below.

From P1, the sub-routes are as follows.

Sub route 4

Sub route 3

Sub route 2

Sub route 1

6 ----11 ---2--- 3 ---10

- Step 6.12: Insert the removed gene 16 at the end of each sub route of P1starting from left toright and check the resultant demand of that sub route. The next check is with gene 16. As per this, insert the gene 16 on the suffix of sub route 4 .

From P1, the sub-routes are as follows.

Sub route 4

Sub route 3

Sub route 2

Sub route 1

6 ----11 ---2

- Step 6.13: Now match the sub route with the vehicle capacity and find out the best possible wayfor inserting the removed genes. If gene 16 is put in the sub route 4 , then the demand for that sub route will be $365 \mathrm{Kg}$, and we don't have a vehicle by which we can fulfil this demand. So, try with another sub route.

From P1, the sub-routes are as follows.

Sub route 4

Sub route 3

Sub route 2

Sub route 1

6 ----11 ---2--- 3 ---10 10 ---12 19 ---18 ----4

- Step 6.14: Now match the sub route with the vehicle capacity and find out the best possible wayfor inserting the removed genes. If gene 16 is put in the sub route 3, then the demand for that sub route will be $305 \mathrm{Kg}$, and we don't have a vehicle by which we can fulfil this demand. So, try with another sub route.

From P1, the sub-routes are as follows.

Sub route 4

Sub route 3

Sub route 2

Sub route 1

6 ----11

- Step 6.15: Now match the sub route with the vehicle capacity and find out the best possible wayfor inserting the removed genes. If gene 16 is put in the sub route2, then the demand for that sub route will be $320 \mathrm{Kg}$, and we don't have a vehicle by which we can full fill this demand. So, try with another sub route. 
From P1, the sub-routes are as follows.

Sub route 4

Sub route 3

Sub route 2

Sub route 1

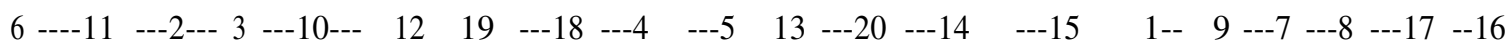

- Step 6.16: Now match the sub route with the vehicle capacity and find out the best possible wayfor inserting the removed genes. If gene 16 is put in the sub route 1 , then the demand for that sub route will be $340 \mathrm{Kg}$, and we don't have a vehicle by which we can fulfil this demand. So, in this case, form a new sub route for gene 16.

From P1, the sub-routes are as follows.

Sub route $4 \quad$ Sub route $3 \quad$ Sub route $2 \quad$ Sub route $1 \quad$ Sub route 5

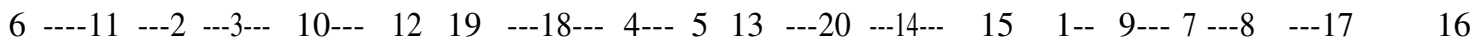

After following this step, new offspring for parent chromosome 1 is as follows.

Offspring 1: 6--- 11--2-- $3-10-12 \quad 19--18-4-5 \quad 13--\quad 20--14-15 \quad 1$--9-- $\quad 7--8-17 \quad 16$

By following the above steps, offspring 2 from parent 2 can also be generated, which is as shown

Below.

Offspring2- $2 \quad---4 \quad---18---\quad 13-2019 \quad---17 \quad---8-16 \quad 1---\quad 7$---6

Accordingly, the final offspring's are as follows:

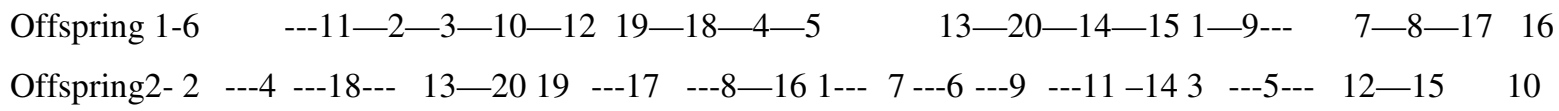

\section{Fitness Function}

The fitness function is a measure of performance for a given problem of interest. In the research reported in this study, the total time of the tour is considered to be the fitness function of the associated chromosome/ offspring, which is a minimization.

Let's assume the demands for 20 customer nodes are as follows:

$1=20 \mathrm{~kg}, 2=40 \mathrm{~kg}, 3=60 \mathrm{~kg}, 4=80 \mathrm{~kg}, 5=100 \mathrm{~kg}, 6=10 \mathrm{~kg}, 7=30 \mathrm{~kg}, 8=50 \mathrm{~kg}, 9=70 \mathrm{~kg}, 10=90 \mathrm{~kg}, 11=365 \mathrm{~kg}$, $12=45 \mathrm{~kg}, 13=55 \mathrm{~kg}, 14=65 \mathrm{~kg} 15=75 \mathrm{~kg}, 16=85 \mathrm{~kg}, 17=95 \mathrm{~kg}, 18=25 \mathrm{~kg}, 19=15 \mathrm{~kg}, 20=5 \mathrm{~kg}$.

Further, let's also assume that the randomly generated population is given as follows:

\begin{tabular}{|l|l|l|l|l|l|l|l|l|l|l|l|l|l|l|l|l|l|l|l|}
\hline 1 & 9 & 3 & 7 & 8 & 17 & 13 & 16 & 20 & 14 & 15 & 10 & 19 & 18 & 4 & 5 & 12 & 6 & 11 & 2 \\
\hline
\end{tabular}

The calculation for Sub route 1: 0-----1----9------3-----7----8-----0

Let's assume that demands are in crates that are used to house the commodity.

Number of crates for $1 \mathrm{~kg}=1$ crate

Assume the unloading time for $1 \mathrm{crate}=1 \mathrm{~min}$.

Total demand of the sub route $1=230 \mathrm{~kg}$

Total distance of the sub route $1=156 \mathrm{Km}$

Vehicle capacity $(\mathrm{A} 1)=300 \mathrm{~kg}$, Speed $=40 \mathrm{~km} /$ hour

Time per $\mathrm{km}=1 / 40$ hour

Time for $156 \mathrm{~km}=156 / 40$ hour $=3.9$ hour, $(234 \mathrm{~min}$. $)$

Time required for unloading the items $=230 * 1=230 \mathrm{~min}$. 
The time required for completing the sub tour 1 is $=234+230 \mathrm{~min}=464 \mathrm{~min}$.

The calculation for Sub route 2: 0-----17-----13-----16-----20-----0

Number of crates for $1 \mathrm{~kg}=1$ crate

Assume the unloading time for 1 crate $=1 \mathrm{~min}$.

The total demand of the sub route $2=285 \mathrm{~kg}$

The total distance of the sub route $2=150 \mathrm{Km}$

Vehicle capacity $(\mathrm{A} 2)=300 \mathrm{~kg}$, Speed $=40 \mathrm{~km} /$ hour Time per $\mathrm{km}=1 / 40 \mathrm{hour}$

Time for $150 \mathrm{~km}=150 / 40$ hour $=3.75$ hour,$(225 \mathrm{~min}$. $)$

Time required for unloading the items $=285 * 1=285 \mathrm{~min}$.

The time required for completing the sub tour $2=225+285 \mathrm{~min}$ is $=510 \mathrm{~min}$.

The calculation for Sub route 3: 0-----14-----15-----10-----19-----18-----0

Number of crates for $1 \mathrm{~kg}=1$ crate

Assume the unloading time for 1 crate $=1 \mathrm{~min}$.

The total demand of the sub route $2=270 \mathrm{~kg}$

The total distance of the sub route $2=190 \mathrm{Km}$

Vehicle capacity $(A 3)=300 \mathrm{~kg}$, Speed $=40 \mathrm{~km} / \mathrm{hour}$ Time per $\mathrm{km}=1 / 40$ hour

Time for $190 \mathrm{~km}=190 / 40$ hour $=4.75$ hour, $(285 \mathrm{~min}$. $)$

Time required for unloading the items $=270 * 1=270 \mathrm{~min}$.

Time required for completing the sub tour $2=285+270 \mathrm{~min}=555 \mathrm{~min}$.

The calculation for Sub route 4: 0-----4-----5-----12-----0

Number of crates for $1 \mathrm{~kg}=1$ crate

Assume the unloading time for $1 \mathrm{crate}=1 \mathrm{~min}$.

The total demand of the sub route $4=225 \mathrm{~kg}$

The total distance of the sub route $4=191 \mathrm{Km}$ Vehicle capacity $(\mathrm{B} 1)=250 \mathrm{~kg}$, Speed $=$ $50 \mathrm{~km} /$ hour Time per $\mathrm{km}=1 / 40$ hour

Time for $191 \mathrm{~km}=191 / 50$ hour $=3.82$ hour, $(229.2 \mathrm{~min}$.)

Time required for unloading the items $=225 * 1=225 \mathrm{~min}$.

Time required for completing the sub tour $4=229.2+225 \mathrm{~min}=454.2 \mathrm{~min}$. The calculation for Sub route 5: 0------6-----9-----11-----2----0

Number of crates for $1 \mathrm{~kg}=1$ crate 
Assume the unloading time for 1 crate $=1 \mathrm{~min}$. Total demand of the sub route $5=85 \mathrm{~kg}$

Total distance of the sub route $5=114 \mathrm{Km}$

Vehicle capacity $(B 2)=250 \mathrm{~kg}$, Speed $=50 \mathrm{~km} / \mathrm{hour}$ Time per $\mathrm{km}=1 / 40$ hour

Time for $114 \mathrm{~km}=114 / 50$ hour $=2.28$ hour, $(136.8 \mathrm{~min}$.

Time required for unloading the items $=85 * 1=85 \mathrm{~min}$.

The time required for completing the sub tour $5=136.8+85 \mathrm{~min}$ is $=221.8 \mathrm{~min}$. Total time required for completing one tour

$=$ Time required for completing the sub tour $1+$ Time required for completing sub tour 2

$+\quad$ Time required for completing sub tour 3 +Time required for completing sub tour 4

$+\quad$ Time required for completing sub tour 5

$=464 \mathrm{~min} .+510 \mathrm{~min} .+555 \mathrm{~min} .+454.2 \mathrm{~min}+221.8 \mathrm{~min} .=2205 \mathrm{~min} .(36.75$ hours $)$ At every node (customer) time window exists.

The interval of the time window for customer $i$ is given as $\left(a_{i}, b_{i}\right)$

If a vehicle of a particular type arrives at the customer $i$, the following cases may arise.

Let the arrival time of the vehicle at the customer i be $A T_{i}$.

- If $A T_{i}<a_{i}$ than the vehicle has to wait up to $a_{i}$ and start service from onwards.

- If $A T_{i}=a_{i}$, than the vehicle, can start service immediately from $a_{i}$ onwards.

- If $A T_{i}>a_{i}$ than the vehicle can start service from $A T_{i}$ onwards.

If the start time plus service time $\left(a_{i}+s_{i}\right)$ or $\left(A T_{i}+s_{i}\right)$ is less than or equal to ${ }^{b_{i}}$, then there is no penalty.

For case (2) if $a_{i}+s_{i} \leq b_{i}$, no penalty

For case (3) if

Otherwise, as stated below, in each case, there is a penalty $(\mathrm{P})$, which is given below.

For case (2) if $a_{i}+s_{i}>b_{i}$, the penalty is given by the following formula.

$P=\left[b_{i}-\left[\left(a_{i}+s_{i}\right)\right]\right.$

For case (3) if $A T_{i}+s_{i}, b_{i}$, the penalty is given by the following formula.

$P=\left[b_{i}-\left(A T_{i}+s_{i}\right)\right]$

The corrected cumulative time of the route up to customer $i$ 
$=\quad$ cumulative time to node $i+P$.

\section{STEPS FOR THE FOUR MODIFIED GENETIC ALGORITHMS}

In this research, an attempt has been made to develop a new variant of GA by changing the selection methods and crossover operators. Additionally, these variants of GA have been tested on various mutation probabilities. The different selection methods with the developed crossover method that are used to develop variants of GA are listed below. A summary of these algorithms are shown in Table 1.

- Rank selection method with N\&P crossover method

- $\quad$ Rowlett Wheel selection method with N\&P crossover method

- $\quad$ Random selection method with N\&P crossover method

- Tournament selection method with N\&P crossover method

Table 1: Summary of Variants of GA Methods

\begin{tabular}{|c|c|c|}
\hline Genetic Algorithm & Selection Method & Crossover Operators \\
\hline N\&PGA1 & Rank Selection & N\&P \\
\hline N\&PGA2 & Rowlett Wheel & N\&P \\
\hline N\&PGA3 & Random & N\&P \\
\hline N\&PGA3 & Tournament & . \\
\hline
\end{tabular}

\section{ALGORITHM N\&PGA1}

The steps of the algorithm, "N\&PGA1" are presented below.

Step 1: Input.

- A number of generation $(\mathrm{G})$ is equal to 30 .

- A number of chromosomes in the population (N) equal to 60 .

- $\quad$ Set the size of the subpopulation (S) to 18 , which is $30 \%$ of $\mathrm{G}$.

- A number of the customer node is (n).

- The demand of the customers.

- $\quad$ Time windows of the customers.

- $\quad$ Service times at customer nodes.

- The number of vehicles.

- The capacity of the vehicles.

- $\quad$ Time window of the depot.

- $\quad$ Mutation probability (p).

- Generation count which begins with a is 1 . 
Step 3: Calculate the fitness value for each chromosome that is $[\mathrm{F}(\mathrm{v})][\mathrm{F}(\mathrm{v})]=$ Total time is taken by the vehicle for completing the tour.

- Calculate and add the penalties if exceeding the upper limits of the time windows.

- $\quad$ Add penalty for each fitness value (in $[\mathrm{F}(\mathrm{v})]$ ).

Step 4: Arrange them in ascending order according to their fitness function values, since this is a minimization problem.

Step 5: Select the top 30\% from them and treat them as the subpopulation S by using the rank selection method.

Step 6: Consider the first two chromosomes from the subpopulation.

Step 7: Perform the N\&P crossover for the current pair of chromosomes.

Step 8: Let us assume that the mutation rate is 0.3 .

Step 9: Generate random number between 0 to 1.

Step 10: If the random number is less than 0.3, then perform mutation on the first offspring in the current pair and go to Step 11; otherwise go to Step 11 without doing mutation on the first offspring in the current pair.

Step 11: Generate random number between 0 to 1 .

Step 12: If the random number is less than 0.3, then perform mutation on the second offspring in the current pair and go to Step 13; otherwise go to Step 13 without doing mutation on the second offspring in the current pair.

Step 13: Calculate the fitness function of each of the offspring at this stage.

Step 14: Compute the sum of the penalties of the tours of each offspring and add it to the fitness function value (time) of that offspring.

Step 15: Subsequently, replace each of the chromosomes of the current pair offspring in the main population with the corresponding offspring along with their modified fitness function value (time + penalty sum).

Step 16: Arrange chromosomes of the main population in ascending order.

Step 17: Repeat the steps from step 4 to step 6 for a predefined number of iterations (Generations).

Step 18: Sort the chromosomes of the main population in ascending order.

Step 19: Treat the topmost chromosome of the sorted population as the final solution for implementation and find tours of their chromosome as the fitness function.

Step 20: Print the results of the final tours with all details along with the sum of time and penalty.

Step 21: Stop.

\section{Algorithm N \& PGA2}

The steps of the algorithm, "N\&PGA2" are presented below. 
The steps of the algorithm "N\&PGA2" are the same as that of the algorithm "N\&PGA1" except step 5 where the Rowlett Wheel selection method is used instead of the Rank Selection Method. Accordingly, the revised Step 5 is defined as Select the top $30 \%$ from them and treat them as the subpopulation S by using the Rowlett wheel selection method.

\section{Algorithm N \& PGA3}

The steps of the algorithm, "N\&PGA3" are presented below.

The steps of the algorithm "N\&PGA3" are the same as that of the algorithm "N\&PGA1" except step 5 where the Random Selection Method is used instead of the Rank Selection Method. Therefore, we define the revised Step 5 as Select the topmost $30 \%$ from them and treat them as the subpopulation $\mathrm{S}$ by using the random selection method.

\section{Algorithm N \& PGA4}

The steps of the algorithm, "N\&PGA4" are presented below.

The steps of the algorithm "N\&PGA4" are the same as that of the algorithm "N\&PGA1" except step 5 where the Tournament Selection Method is used instead of the rank selection method. In this case, also we revise Step 5 as Select the topmost $30 \%$ from them and treat them as the subpopulation $\mathrm{S}$ by using the Tournament selection method.

\section{COMPARISON OF GENETIC ALGORITHMS}

This chapter presents a comparison of the four algorithms, which are developed in this research.

The four genetic algorithms are N\&PGA1, N\&PGA2, N\&PGA3 and N\&PGA4.

A complete factorial experiment has been designed with three factors, viz. Problem Size, Method and Mutation Probability to compare the algorithms.

\section{Complete Factorial Experiment}

It is assumed that the fitness function value of the HVRPTW depends on three factors, viz. Problem Size (Factor A), Method (Factor B) and Mutation Probability (Factor C) to compare the algorithms. Hence, a complete factorial experiment with these three factors and with three replications in each of the experimental combinations is designed. The levels of the Factor $\mathrm{A}$ are 10, 15, 20, 15, 20, 25, 30, 35, 40, 45, 50, 55 and 60. The levels of the Factor B are N\&PGA1, N\&PGA2, N\&PGA3 and N\&PGA4. The levels of the mutation probability are $0.1,0.2$ and 0.3 .

\section{ANOVA Model}

The ANOVA model of this complete factorial experiment is shown below.

$$
Y_{i j k l}=\mu+A_{i}+B_{j}+A B_{i j}+C_{k}+A C_{i k}+B C_{j k}+A B C_{i j k}+e_{i j k l}
$$

where,

$\mu$ Represents the overall mean

$Y_{i j k l}$ is the response in terms of the total time taken for completing the tour in the replication under $i^{\text {th }}$ level of the factor Problem Size, ${ }^{\text {th }}$ level of the factor Method and $k^{\text {th }}$ level of the factor Mutation Probability. 
$A_{i}$ is the effect of the $i^{\text {th }}$ level of the factor Problem Size on the response in terms of the total time taken for completing the tour

$B_{j}$ is the effect of the $j^{\text {th }}$ level of the factor Method on the response in terms of the total time taken for completing the tour

$A B_{i j}$ is the effect of the $i^{\text {th }}$ level of the factor Problem Size and the $j^{\text {th }}$ level of the factor Method on the response in terms of the total time taken for completing the tour.

$C_{k}$ is the effect of the ${ }^{t h}$ level of the factor Mutation probability on the response in terms of the total time taken for completing the tour.

$A C_{i k}$ is the effect of the $i^{t h}$ level of the factor Problem Size and the $k^{\text {th }}$ level of the factor Mutation probability on the response in terms of the total time taken for completing the tour.

$B C_{j k}$ is the effect of the level of the factor Method and the level of the factor Mutation probability on the response in terms of the total time taken for completing the tour.

$A B C_{i j k}$ is the effect of the level of the factor Problem Size. Level of the factor Method and the level of factor C (Mutation probability) on the response in terms of the total time taken for completing the tour.

$e_{i j k l}$ is the random error associated with the response in terms of the total time taken for completing the tour of the ${ }^{l^{t h}}$ replication under the $i^{\text {th }}$ level of factor A, level of the factor Method and the $k^{\text {th }}$ level of the factor Mutation Probability.

Hypothesis for Problem Size (Factor A)

- $\mathrm{H}_{\mathrm{O}}$ : There are no significant differences among the levels of Problem Size in terms of the total time taken by the heterogeneous vehicles.

- $\mathrm{H}_{1}$ : There are significant differences among the levels of problem sizes in terms of the total time taken by the heterogeneous vehicles.

Hypothesis for Method (Factor (B)

- $\mathrm{H}_{\mathrm{O}}$ : There are no significant differences among the levels of Method in terms of the total time taken by the heterogeneous vehicles.

- $\mathrm{H}_{1}$ : There are significant differences among the levels of Method in terms of the total time taken by the heterogeneous vehicles.

Hypothesis for interaction term Problem Size X Method

- $\mathrm{H}_{\mathrm{O}}$ : There is no interaction between the Problem Size and the Method and in terms of the total time taken by the heterogeneous vehicles. 
- $\mathrm{H}_{1}$ : There is an interaction between the Problem Size and the Method in terms of the total time taken by the heterogeneous vehicles.

Hypothesis for Mutation Probability (Factor C)

- $\mathrm{H}_{\mathrm{O}}$ : There are no significant differences among the levels of Mutation Probability in terms of the total time taken by the heterogeneous.

- $\mathrm{H}_{1}$ : There are significant differences among the levels of Mutation Probability in terms of the total time taken by the heterogeneous vehicles.

Hypothesis for interaction term Method X Mutation Probability

- $\mathrm{H}_{\mathrm{O}}$ : There is no interaction between the Method and Mutation Probability in terms of the total time taken by the heterogeneous vehicles.

- $\mathrm{H}_{1}$ : There is an interaction between the Method and Mutation Probability in terms of the total time taken by the heterogeneous vehicles.

Hypothesis for interaction term 'Problem Size * Mutation Probability'

- $\mathrm{H}_{\mathrm{O}}$ : There is no interaction between the Problem Size and Mutation Probability in terms of the total time taken by the heterogeneous vehicles.

- $\mathrm{H}_{1}$ : There is an interaction between the Problem Size and Mutation Probability in terms of the total time taken by the heterogeneous vehicles.

Hypothesis for interaction term Problem Size X Method X Mutation Probability

- $\quad \mathrm{H}_{\mathrm{O}}$ : There is no interaction between the Problem Size, Method and Mutation Probability in terms of the total time taken by the heterogeneous vehicles.

- $\mathrm{H}_{1}$ : There is an interaction between the Problem Size, Method and Mutation Probability in terms of the total time taken by the heterogeneous vehicles.

\section{Results of Factorial Experiment and ANOVA}

As per the complete factorial experiment designed in this research, the results after executing the four algorithms for different mutation probabilities are presented in Table 2. The results of ANOVA for the data shown in the Table 2 are shown in Table 3.

Results obtained using four variants are compared with each other to verify whether there are any significant differences among these algorithms.

Assuming a five per cent significance level, it is evident from the results of Table 3 that there are significant differences between the four methods adopted in this study in terms of the response variable. This means that on an average the total time taken by the heterogeneous vehicles for completing the tour differs from each other. More specifically, we observe the following results. 
Table 2: Results of Fitness Function

\begin{tabular}{|c|c|c|c|c|c|c|c|c|c|c|c|c|c|}
\hline \multirow{3}{*}{\multicolumn{2}{|c|}{ NODES }} & \multirow{3}{*}{$\begin{array}{l}\mathrm{M} R \\
=0.1\end{array}$} & \multirow{3}{*}{\begin{tabular}{|c|} 
N\&PGAl \\
$M \mathbb{R}$ \\
$=0.2$ \\
\end{tabular}} & \multirow{3}{*}{$\begin{array}{l}\text { MA } \\
=0.3\end{array}$} & \multirow{3}{*}{$\begin{array}{l}\mathrm{MR} \\
=0.1\end{array}$} & \multirow{3}{*}{$\begin{array}{c}\text { N\&PGA? } \\
\text { MR } \\
=0.2\end{array}$} & \multirow{3}{*}{$\begin{array}{c}\text { MA } \\
=0.3\end{array}$} & \multirow{3}{*}{$\begin{array}{l}\text { MR } \\
=0.1\end{array}$} & \multirow{3}{*}{$\begin{array}{c}\text { N\&PGA3 } \\
M \mathbb{R} \\
=0.2\end{array}$} & \multirow{3}{*}{$\begin{array}{l}\text { MA } \\
=0.3\end{array}$} & \multirow{3}{*}{$\begin{array}{l}\text { MR } \\
=0.1\end{array}$} & \multirow{3}{*}{$\begin{array}{c}\text { N\&PGA3 } \\
\text { MR } \\
=0.2\end{array}$} & \multirow{3}{*}{$\begin{array}{l}\text { MA } \\
=0.3\end{array}$} \\
\hline & & & & & & & & & & & & & \\
\hline & & & & & & & & & & & & & \\
\hline & Rl & 905.8 & 833.4 & 821.6 & 708.2 & 685.8 & 676.2 & 868.4 & 840.8 & 854.8 & 937.6 & 914.2 & 888 \\
\hline \multirow[t]{3}{*}{10} & $\mathrm{R} 2$ & 806 & 883.2 & 839 & 652.2 & 727.6 & 746.8 & 818.6 & 889.8 & 898.6 & 886 & 932.8 & 961.8 \\
\hline & R3 & 667.8 & 862.2 & 753.6 & 569.8 & 744.4 & 788.2 & 727.4 & 900.4 & 793.4 & 767.6 & 996.2 & 861.6 \\
\hline & Rl & 1161.2 & 1241.6 & 1032.6 & 1015.2 & 1114 & 1115.4 & 1158 & 1262.8 & 1105.2 & 1235.2 & 1276 & 1101.8 \\
\hline \multirow[t]{3}{*}{15} & $\mathrm{R} 2$ & 1091.8 & 1120 & 1112.2 & 1007.6 & 1013.6 & 1044.2 & 1091.6 & 1168.4 & 1142.8 & 1244 & 1283.4 & 1132.8 \\
\hline & R3 & 1203.6 & 1168.6 & 1083 & 1016.4 & 1060 & 1054.2 & 1247.2 & 1253 & 1020.4 & 1264.2 & 1269.4 & 1195 \\
\hline & Rl & 1468.6 & 1691.8 & 1472.8 & 1457.4 & 1500.1 & 1490.2 & 1588 & 1592 & 1521.6 & 1689.8 & 1716.6 & 1555.8 \\
\hline \multirow[t]{3}{*}{20} & $\mathrm{R} 2$ & 1641.4 & 1687.4 & 1485.8 & 1517.8 & 1520.4 & 1560.4 & 1656.8 & 1665 & 1444 & 1757.8 & 1684 & 1564.8 \\
\hline & R3 & 1421.2 & 1525.4 & 1455.6 & 1340.8 & 1354.2 & 1378.8 & 1400 & 1512.2 & 1564.8 & 1959.2 & 1549.4 & 1640 \\
\hline & Rl & 1923.4 & 1906.1 & 1972.4 & 1751 & 1778.4 & 1756.2 & 1960.8 & 1934.8 & 1995.6 & 2021.4 & 1968 & 2089.6 \\
\hline \multirow{3}{*}{25} & R2 & 1935 & 2036.4 & 2040 & 1902.4 & 1943.5 & 1841.4 & 2077.6 & 2094.4 & 1907.8 & 2116 & 2059.2 & 2035.8 \\
\hline & R3 & 1928.2 & 1849.2 & 2069.4 & 1771.2 & 1685 & 1746 & 1855.4 & 1874.4 & 1973.2 & 1998.4 & 1944.8 & 2171.2 \\
\hline & $\mathrm{Rl}$ & 2280 & 2235.6 & 2190.6 & 2113 & 2027.8 & 2044.8 & 2310.2 & 2141.4 & 2156.4 & 2345 & 2222.8 & 2108.6 \\
\hline \multirow[t]{3}{*}{30} & $\mathrm{R} 2$ & 2095 & 2169.7 & 2051.9 & 1885.4 & 2043 & 2087.6 & 2121.8 & 2248.2 & 2127.8 & 2167.2 & 2133.2 & 2209 \\
\hline & R3 & 2747.8 & 2093.4 & 2167.4 & 2073 & 1997 & 2003.4 & 2160.4 & 2222.8 & 2180.8 & 2217.6 & 2076.6 & 2257.4 \\
\hline & $\mathrm{Rl}$ & 2535.2 & 2589 & 2760.7 & 2475.2 & 2469.2 & 2502.4 & 2905 & 2526 & 2570.6 & 2676 & 2657.2 & 2775.4 \\
\hline \multirow[t]{3}{*}{35} & $\mathrm{R} 2$ & 2558.2 & 2520.2 & 2588.2 & 4306.9 & 2334.6 & 2363 & 2514.8 & 2544.2 & 2807 & 2618.2 & 2639.4 & 2671 \\
\hline & R3 & 2582.6 & 2790 & 2607.2 & 2486.6 & 2585.2 & 2701.2 & 2592.2 & 2783 & 2874 & 2627.8 & 2878.8 & 2771.2 \\
\hline & Rl & 3203 & 3407.2 & 3332.9 & 2732.4 & 3150.2 & 3289.7 & 2960 & 3439.3 & 3233 & 2638 & 3423.3 & 3205 \\
\hline \multirow[t]{3}{*}{40} & R? & 3148.6 & 3112.2 & 3005 & 3128.3 & 3196 & 2984.5 & 3144.7 & 3313.6 & 2957.3 & 3342.6 & 3261.5 & 3031.3 \\
\hline & R3 & 3113.2 & 3326.2 & 3108.1 & 2900.3 & 2986.7 & 3103.1 & 3071.8 & 3333.4 & 3054.4 & 3139.2 & 3367.8 & 3187.5 \\
\hline & Rl & 3689.5 & 3669.9 & 3604.8 & 3326.6 & 3526.3 & 3413.5 & 3485.8 & 3624.3 & 3590.4 & 3578.7 & 3758.6 & 3697.7 \\
\hline \multirow[t]{3}{*}{45} & $\mathrm{R}_{2}$ & 3716.6 & 3467.2 & 3636.1 & 3485.1 & 3593 & 3369.4 & 3639.8 & 3599.1 & 4100.4 & 3754.3 & 3786.8 & 3627.9 \\
\hline & $\mathrm{R} 3$ & 3667.1 & 3518.6 & 3511.8 & 3305.1 & 3349.2 & 3252.6 & 3473.9 & 3493.4 & 3477 & 3581.5 & 3671.2 & 3321.5 \\
\hline & Rl & 3919.5 & 3981.7 & 3811.5 & 3694.5 & 3854.3 & 3797.9 & 3969.5 & 3884.2 & 4019.1 & 3928.6 & 4054.8 & 4096.1 \\
\hline \multirow[t]{3}{*}{50} & $\mathrm{R} 2$ & 3995 & 3833.3 & 3976.5 & 4059.9 & 3685.2 & 3510.3 & 4091 & 3958.1 & 4447.9 & 3973.6 & 3948.7 & 4095.5 \\
\hline & R3 & 3884.2 & 4152.7 & 3980.2 & 3665 & 4055.6 & 3932.9 & 3819.4 & 3988.3 & 3956.8 & 3816 & 4044 & 4131.3 \\
\hline & $\mathrm{Rl}$ & 4460.2 & 4661.2 & 4501.8 & 4410.2 & 4418.3 & 4463.3 & 4480.9 & 4501 & 4426.5 & 4551 & 4646.1 & 4424 \\
\hline \multirow[t]{3}{*}{55} & $\mathrm{R} 2$ & 4482 & 4603.1 & 4448.5 & 4313.8 & 4595.2 & 4388.1 & 4364.7 & 4693.4 & 5081 & 4517.9 & 4723 & 4671.3 \\
\hline & $\mathrm{R} 3$ & 4444 & 4447.3 & 4309.7 & 4404.5 & 4451.3 & 4403 & 4391.2 & 4385.5 & 4482.2 & 4387.2 & 4525.2 & 4445.8 \\
\hline & $\mathrm{Rl}$ & 5205.6 & 5449.5 & 5262.2 & 5138.2 & 5096.8 & 5170.9 & 5174.4 & 5197.2 & 5290.1 & 5228 & 5469.2 & 5453.8 \\
\hline \multirow[t]{2}{*}{60} & $\mathrm{R} 2$ & 5747 & 5285.5 & 5193.8 & 5091.8 & 4753.1 & 5196 & 5413.8 & 5084.9 & 5281.7 & 5415.6 & 5299.3 & 5300.8 \\
\hline & R3 & 4986.7 & 5223.1 & 5131.9 & 5051.3 & 5168.3 & 4963.4 & 5062.6 & 5291.2 & 5173.9 & 5088.9 & 5404.5 & 5115 \\
\hline
\end{tabular}

- There are significant differences among the levels of "Problem Size (A)" in terms of the total time taken for completing the tour.

- There are significant differences among the levels of "Method (B)" in terms of the total time taken for completing the tour.

- There are no significant differences among the combinations of the levels of "Problem Size (A) and Method (B)" in terms of the total time taken for completing the tour.

- There are no significant differences among the levels of "Mutation Probability (C)" in terms of the total time taken for completing the tour.

- There are no significant differences among the combinations of the levels of "Problem Size (A)" and "Mutation Probability (C)"

- There are no significant differences among the combinations of the levels of "Problem Size (A)", "Method (B)" and "Mutation Probability (C)"

Since there are significant differences among the algorithms, the next task is to find the best algorithm among them, which is carried out using Duncan multiple range tests, as shown in the next section. 
Table 3: Results of ANOVA

\begin{tabular}{|l|c|c|c|c|c|}
\hline \multicolumn{1}{|c|}{ Source } & Sum of Squares & df & Mean Square & F & Sig. \\
\hline Problem size (A) & 724958083.120 & 10 & 72495808.312 & 3074.249 & 0 \\
\hline Ga methods (B) & 1689909.725 & 3 & 563303.242 & 23.887 & 0 \\
\hline $\mathrm{A} * \mathrm{~B}$ & 489388.326 & 30 & 16312.944 & .692 & .887 \\
\hline Mutation probability (C) & 82419.612 & 2 & 41209.806 & 1.748 & .176 \\
\hline $\mathrm{A} * \mathrm{C}$ & 672243.239 & 20 & 33612.162 & 1.425 & .110 \\
\hline $\mathrm{B} * \mathrm{C}$ & 130659.966 & 6 & 21776.661 & .923 & .478 \\
\hline $\mathrm{A} * \mathrm{~B} * \mathrm{C}$ & 1351119.312 & 60 & 22518.655 & .955 & .573 \\
\hline Error & 6225550.187 & 264 & 23581.629 & & \\
\hline Total & 3812498739.040 & 396 & & & \\
\hline Corrected Total & 735599373.487 & 395 & & & \\
\hline
\end{tabular}

\section{Duncan Multiple Range Test}

From the results obtained from ANOVA, it is evident that the proposed four variants of the genetic algorithm differ significantly from each other. Hence, Duncan's multiple range test is used to select the best method in terms of the minimum total time.

- $\quad$ Step 1: Arrange the treatment means of the GA Methods in descending order as shown in Table 4.

Table 4: Means of Four Different GA Methods in Descending Order

\begin{tabular}{|c|c|c|c|}
\hline N \& PGA 4 & N \& PGA 3 & N \& PGA 1 & N \& PGA 2 \\
\hline 2857.0848 & 2811.6030 & 2800.7646 & 2680.3980 \\
\hline
\end{tabular}

- $\quad$ Step 2: The standard errors is obtained using the following formula:

$$
\mathrm{SE}_{\mathrm{Y} . \mathrm{j}}=
$$

From the ANOVA table, the mean sum of squares (MSS Error $)$ is as given below along with the number of observations under each GA Methods (n).

$$
\text { MSS }_{\text {Error }}=23581.629 \text { and } n=33
$$

The standard error is as computed as shown below.

$$
\mathrm{SE}_{\mathrm{Y} . \mathrm{j}}=\quad\left(\mathrm{MSS}_{\mathrm{Error}} / \mathrm{n}\right)^{0.5}=\sqrt{\frac{23581.629}{33}}=26.73
$$

- Step 3: Three significant ranges from the Duncan table of for $\mathrm{j}=2,3$ and 4 ; $\mathrm{df}=264$ and $\alpha=0.05$ are shown in Table 5 .

Table 5: Values of $\mathbf{J}$ and its Corresponding Significant Ranges

\begin{tabular}{|c|c|c|c|}
\hline $\mathbf{J}$ & $\mathbf{2}$ & $\mathbf{3}$ & $\mathbf{4}$ \\
\hline Significant Range & 2.77 & 2.92 & 3.02 \\
\hline
\end{tabular}

- Step 4: Least Significant Ranges (LSR) are calculated by multiplying the significant ranges with the standard error obtained in Step 2 that are shown in Table 6. 
Table 6: Least Significant Ranges

\begin{tabular}{|l|l|}
\hline J & Least Significant Range (LSR) \\
\hline $22.77 * 26.73=74.05$ \\
\hline $32.92 * 26.73=78.05$ \\
\hline $43.02 * 26.73=80.72$ \\
\hline
\end{tabular}

Step 5: The means of the GA Methods in their descending order along with actual range and least significant ranges are shown in Fig.1.

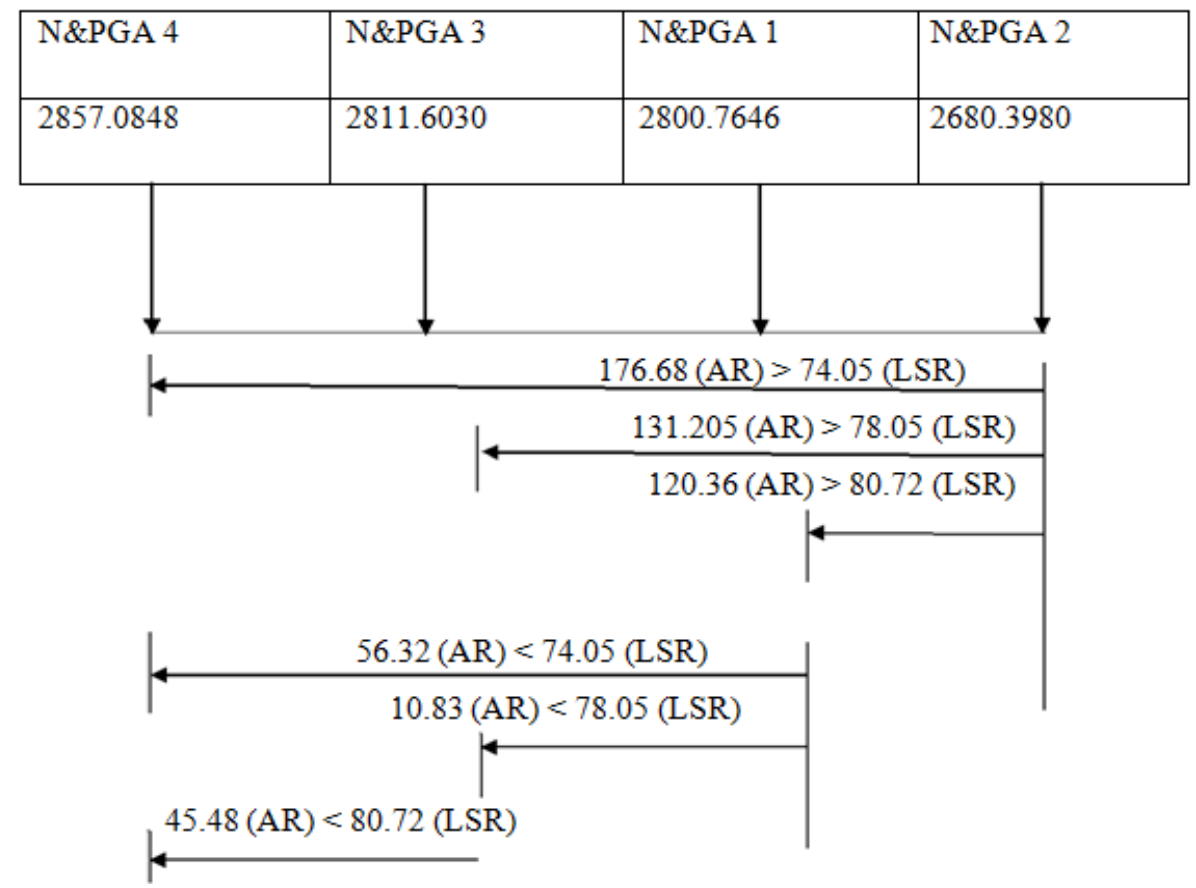

Figure 1: Actual Ranges (ARs) and LSR Values.

Based on the Fig.1, it is clear that the method N\&PGA2 is superior to all methods (GA methods), because the actual range is greater than the respective LSR values with other methods (GA methods).

\section{CONCLUSIONS}

In the research reported in this paper, HVRPTW has been addressed. The four variants of genetic algorithm have been developed by varying selection methods viz. N\&PGA1, N\&PGA2, N\&PGA3 and N\&PGA4. These methods are tested on various problem sizes 10, 15, 20, 25,30,35,40,45,50,55, and 60 as nodes and Mutation Probability as 0.1, 0.2 and 0.3. The number of replications used under each experimental combination is 3. The source codes of the four GA Methods are developed and executed in C\# on the .NET platform. The results obtained are tested for statistical significance using a complete factorial experiment with three factors, viz. Problem Size, and Method and Mutation probability. Since there are significant differences among the methods, Duncan multiple range tests have been carried out to find the best GA Method. From the Duncan multiple Range test, the GA Method "N\&PGA2" is proved to be the best method, which is a variant of GA which uses Rowlett Wheel selection method and N\&P crossover to create offspring. 


\section{REFERENCES}

1. Alvarenga, G.B. Mateus, G.R., and Tomi G. De, (2007) A genetic and set partitioning two-phase approach for the vehicle routing problem with time windows, Computers \&Operations Research, (34),1561-1584

2. Amador-Fontalvo, Jaime, Paternina-Arboleda, Carlos, Montoya-Torres, and Jairo. (2014). Solving the heterogeneous vehicle routing problem with time windows and multiple products via a bacterial meta-heuristic. International Journal of Advanced Operations Management, (6), 81 - 100.

3. B. Ombuki, B. Ross, and F. Hanshar, (2006) Multi-objective genetic algorithm for vehicle routing problem with time windows, Applied Intelligence, (24), 17-30.

4. Behrouz Afshar-Nadjafi, and Alireza Afshar-Nadjafi, (2017) A constructive heuristic for time-dependent multi-depot vehicle routing problem with time-windows and heterogeneous fleet, Journal of King Saud University - Engineering Sciences, 29(1), 29-34.

5. Bräysy, Olli, Dullaert, Wout, Hasle, Geir, Mester, David Gendreau, and Michel. (2008). An Effective Multirestart Deterministic Annealing Metaheuristic for the Fleet Size and Mix Vehicle-Routing Problem with Time Windows. Transportation Science, (42), 371-386.

6. Çăgrı Koç, Tolga Bektaş, Ola Jabali, and Gilbert Laporte, (2015) A hybrid evolutionary algorithm for heterogeneous fleet vehicle routing problems with time windows, Computers \& Operations Research, (64), 11-27,

7. Ceschia S., Luca Di G., and Andrea S. (2011), Tabu search techniques for the heterogeneous vehicle routing problem with time windows and carrier-dependent costs Journal of Scheduling, (14), 601-615

8. De la Cruz J.J., Paternina-Arboleda C.D., and Cantillo V. Montoya-Torres J.R.A (2013), two-pheromone trail ant colony system-Tabu search approach for the heterogeneous vehicle routing problem with time windows and multiple products Journal of Heuristics, (19), 233-252

9. Despaux, F. and Basterrech, S. (2016). Multi-trip vehicle routing problem with time windows and heterogeneous fleet. International Journal of Computer Information Systems and Industrial Management Applications, (8), 355-363.

10. Dondo, R., and Cerda, J. (2007). Discrete Optimization a cluster-based optimization approach for the multi-depot heterogeneous fleet vehicle routing problem with time windows, European Journal of Operational Research, (176), 1478-1507.

11. Golden, B.L. Assad, A. A., Levy, L., and Gheysens, F. (1984). The fleet size and mix vehicle routing problem. Computers \& Operations Research, (11), 49-66.

12. Hadiuzzaman, Md, et al. "Development of delay model for non-lane based traffic at signalized intersection." International Journal of Civil Engineering 3 (2014): 67-82.

13. Haque, SyrrinaAhasn Ali. "The Heterogeneous Realm of South Asian Literature in Determining the Public Sphere of Partition." International Journal of Humanities and Social Sciences (2016): 83-90.

14. Hu WB, Liang HL, Peng C, Du B, and Hu Q (2013) A hybrid chaos-particle swarm optimization algorithm for the vehicle routing problem with time window. Entropy (15), 1247-1270

15. Jabali, O., and Laporte, G. (2016). Thirty years of heterogeneous vehicle routing, European Journal of Operational Research, (249), 1-21.

16. Jair J. Cruz, Carlos D. Paternina-Arboleda, Victor Cantillo, Jairo R. and Montoya-Torres. 2013. A two-pheromone trail ant colony system--tabu search approach for the heterogeneous vehicle routing problem with time windows and multiple products - Journal of Heuristics, (19), 233-252. 
17. Jebari, Khalid. (2013). Selection Methods for Genetic Algorithms. International Journal of Emerging Sciences, (3), 333-344.

18. Kabcome P, and Mouktonglang T, (2015) Vehicle routing problem for multiple product types, compartments, and trips with soft time windows. International journal of mathematical science, (2015), 9-18.

19. Kallel, S., and Boujelbene, Y. (2013). The heterogeneous routing problem with stochastic demand and client priority solving by the genetic clustering algorithm. Journal of Global Research in Computer Science, (3), 74-79

20. Kumar, S.N. and Panneerselvam, R. (2015) A Time-Dependent Vehicle Routing Problem with Time Windows for E-Commerce Supplier Site Pickups Using Genetic Algorithm. Intelligent Information Management, (7), 181-194.

21. Liu, S., 2013. A hybrid population heuristic for the heterogeneous vehicle routing problems. Transportation Research Part E, (54), 67-78.

22. M. Gendreau, G. Laporte, C. Musaraganyi, and E.D. Taillard (1999)A tabu search heuristic for the heterogeneous fleet vehicle routing problem Computers \& Operations Research, (26), 1153-1173

23. Naik, R. T., and C. Nilesh. "Emission characteristic of a high speed diesel engine." International Journal of Mechanical Engineering, 5, 2936 (2016).

24. Nagle and Paneerselvam (2016), Literature Review on Heterogeneous Vehicle Routing Problem. Conference Proceedings in $3 i$ Intelligence, Innovation and Inclusion - Best Practices for Global Excellence. Editor, Chitra Sivasundaram. Kasilingam, B. Rajeshwari, R. Vijay Nicole Imprints Ltd. Chennai, 879 to 896.

25. Kirci, P., "An optimization algorithm for a capacitated vehicle routing problem with time windows", Sadhana, (41), 519-529, 2016.

26. Padmabati Chand and J R Mohanty. (2013) A Multi-objective Vehicle Routing Problem using Dominant Rank Method. IJCA Proceedings on International Conference on Distributed Computing and Internet Technology 29-34, January 2013.

27. Panneerselvam, R. (2016). Design and Analysis of Algorithms. Second Edition, PHI Learning, New Delhi

28. Pierre, D. M. and Zakaria, N. 2017. Stochastic partially optimized cyclic shift crossover formulate-objective genetic algorithms for the vehicle routing problem with time-windows. Applied Soft Computing, (3838), 14-28.

29. Prins, C., 2009. 'Two memetic algorithms for heterogeneous fleet vehicle routing problems'. Engineering Applications of Artificial Intelligence. (22), 916-928.

30. Sachin Kumar Nagle and Panneer selvam R (2018), Study of Crossover operators of Genetic Algorithm \& Development of New Crossover Operator to Solve Heterogeneous Vehicle Routing Problem with Time Windows, International Journal of Production Technology and Management, 9(2), 1-22.

31. Sadoun, K., 2006. Heterogeneous fleet vehicle routing problem with time windows and nonlinearly penalized delays. J. Applied Sciences, (6), 1969-1973.

32. Shannon Pace, Ayad Turky, I. Moser, and Aldeida Aleti,(2015) Distributing Fibre Boards: A Practical Application of the Heterogeneous Fleet Vehicle Routing Problem with Time Windows and Three-dimensional Loading Constraints, Procedia Computer Science, (51), 2257-2266,

33. Хu, Y. (2012). A New Variable Neighbourhood Search Algorithm for the Multi-Depot Heterogeneous Vehicle Routing Problem with Time Windows, Electronic Notes in Discrete Mathematics, (39), 289-296. 